\title{
INVESTIGACIÓN/RESEARCH
}

\section{LA COMUNICACIÓN EN EL EMPODERAMIENTO DE LA CULTURA EMPRENDEDORA}

Juan De Lucas Osorio: Universidad de Málaga. España.

jdelucasosorio@gmail.com

\section{RESUMEN}

Resaltar el valor de los canales y contenidos de los medios de comunicación como proceso socializador para adoptar la cultura emprendedora, de la que tanto se comenta e impone debido a los cambios socioeconómicos, permitiendo a la sociedad entender, asimilar y aceptar esta nueva forma de actuar en la realidad.

PALABRAS ClaVe: Nuevas Tecnologías - Cultura Emprendedora - Medios de Comunicación - Innovación

\footnotetext{
${ }^{1}$ Autor correspondiente:

Juan De Lucas Osorio: Facultad de Ciencias de la Comunicación de la Universidad de Málaga. España.

Correo: jdelucasosorio@gmail.com
} 


\section{THE COMMUNICATION IN EMPOWERING ENTREPRENEURIAL CULTURE}

\section{ABSTRACT}

Highlight the value of channels and content of the media as a socializing process to adopt an entrepreneurial culture, of which so much is said and imposes due to socioeconomic changes, allowing society to understand it, assimilate and accept this new way of creating reality.

KEYWORDS: New Media - Culture of Entrepreneurship - Media - Innovation -

\section{INTRODUCCIÓN}

Vivimos un proceso de cambio político, económico y social, donde las estructuras establecidas hasta el momento comienzan a tambalearse sobre una población joven formada con ganas de que este cambio ocurra de la manera más eminentemente posible. Un flanco de este proceso de transformación del sistema que conocemos, viene aportado por el concepto de cultura emprendedora, o lo que es lo mismo, la potencialidad de las habilidades de la persona a través de la creatividad, innovación, responsabilidad y emprendimiento. La filosofía de cultura emprendedora pretende potenciarse desde el sistema educativo, instaurando nuevas iniciativas y actividades que fomenten estos cuatro valores, en todos los niveles del sistema educativo español: Educación Primaria, Educación Secundaria Obligatoria, Bachiller y Universidades.

Los nuevos contenidos, cimentados en la cultura emprendedora, resaltar las habilidades y competencias de las personas, irían destinados a una población juvenil ilusionada con la idea de crear sus propios proyectos, pero una variedad y heterogeneidad de obstáculos que le impiden llevar a cabo su sueño, su ilusión. Ver el fracaso como un fin, en vez de como una oportunidad para aprender, la sobrevaloración de la opinión de su entorno más cercano, el desconocimiento de antecedentes emprendedores o la falta de optimización de recursos, son las causas principales que frenan el espíritu emprendedor.

Ante esta situación de incentivar desde los centros educativos una masa de jóvenes con ganas pero con reticencias a aplicar lo aprendido ante una sociedad dictatorial sin conocimientos sobre cultura emprendedora, son los medios de comunicación los encargados de gestionar esta relación para crear una sinergia y que el motor emprendedor se ponga en marcha en la sociedad.

A través de los canales de comunicación, como televisión, prensa, Internet, cine o la música, y de la creación de contenidos, tendrán la oportunidad de acercar la cultura emprendedora a todos los públicos, educándolos de una manera cercana y no formal en esta nueva filosofía. Narrando ejemplos de personalidades emprendedoras, aportarán confianza y seguridad a los espectadores emprendedores, inculcando el 
valor de la ilusión y creación de sueños mediante el cine o las series de televisión, o la posibilidad de conocer la opinión de quienes nos rodea sobre nuestro proyecto a través de simuladores en redes sociales, serán las características fundamentales de los medios de comunicación en este triángulo donde convergen la cultura emprendedora, la educación y los medios de comunicación.

"Bart Conner, de 40 años, cuando tenía 6 años, descubrió que podía andar sobre las manos con la misma facilidad que con los pies. Luego descubrió que podía subir y bajar escaleras sobre sus manos, una habilidad que no le servía de mucho, pero al menos era muy popular en las fiestas. Su madre, tras pensarlo mucho, cuando Bart tenía 8 años habló con la escuela a la que iba y les preguntó si podrían llevar a Bart al centro gimnástico donde vivían Illinois. Y así lo hicieron. Bart recuerda el primer día que llegó allí, al centro de gimnasia, recuerda que al abrir la puerta pensó que era como Disneylandia, donde había trapecios, rampas, trampolines y añadió era embriagador. Bart comenzó a ir cada día tan a menudo como podía. Diez años después desfilaría en el acto de apertura de las Olimpiadas de Montreal representando al equipo de gimnasia masculina de os Estados Unidos. Llegó a ser el deportista más laureado del deporte gimnástico estadounidense. Ahora vive en Norman (Oklahoma) y está casado con Nadia Comaneci, primera gimnasta femenina que logró una nota perfecta de dieces, tienen un hijo llamado Dilán y dirigen un gimnasio fabuloso, además de ser dos figuras destacadas del movimiento Special Olympics, entre ambos han ayudado a sacar a la luz las capacidades de millones de atletas con necesidades especiales. La madre de Bart, cuando su hijo tenía 8 años le podía haber dicho, para resulta molesto, dedicate a lo que debes hacer: estudiar, los deberes. Pero no lo hizo, se dio cuenta que ahí había algo importante para él, los niños lanzan estas señales constantemente."

El ejemplo de Bart, narrado por su amigo Ken Robinson (Redes 2011), es ilustrativo de cómo el emprendimiento cultural surge a cada instante, y si se le otorga los canales adecuados para potenciarlo, sin coacción y adoptando las herramientas necesarias para desarrollarlo puede tener excelentes resultados.

Cada día, son muchos los Barts que no son apoyados, y se les enseña a dedicarse a lo que sociedad cree que es importante, estudiar, seguir el camino que todos siguen para así tener un futuro igual que el resto. Esta filosofía sin lugar para el emprendimiento se traduce en una tasa del $4 \%$ de jóvenes emprendedores o lo que es lo mismo 185.300 emprendedores del total de 4.639 .200 jóvenes con una edad comprendida entre los 15 y 29 años, muy por detrás de la media de emprendedores en Europa situada en el 40\%, según el Informe de Jóvenes Emprendedores-Unión Europea (ATA Federación de Autónomos, 2011).

Examinando el panorama actual, encontramos una situación azotada por los mercados bursátiles a la baja, donde únicamente hay lugar para la innovación, la creatividad, la responsabilidad, y el emprendimiento, los cuatro pilares en los que se sostiene la cultura emprendedora (BOJA núm. 137, 2011, p.1). Vivimos en un mundo donde la vanguardia, lo original y lo extrovertido vende, se compra, pero ¿cómo conseguirlo con jóvenes arraigados en un sistema que les enseña a no ser trasgresores? En la 
educación actual, se destinan más hora al desarrollo del lóbulo frontal izquierdo, nuestra parte analítica y científica, que al desarrollo del lóbulo frontal derecho, de donde surge la creatividad y la espontaneidad. En España durante el curso 2008/09 un total de $50,1 \%$ de jóvenes cursaron bachillerato de Humanidades y Ciencias Sociales, un $45,4 \%$ se decantaron por el Bachillerato de Ciencias y Tecnologías, y únicamente un $4 \%$ se matriculó en la modalidad de Artes ( $0,6 \%$ no distribuido por modalidad). Pero si nos trasladamos a los resultados, es decir después de habernos matriculados en una opción, el porcentaje para las Artes es más desalentador: $32,6 \%$ de aprobados en Ciencias Sociales, un $26,8 \%$ de aprobados en Ciencias de la Salud, en CientíficoTécnico un $22,0 \%$, le sigue Humanidades con un $11,9 \%$, un $4,0 \%$ de aprobados para modalidades combinadas y en el último lugar, un porcentaje de aprobado del $2,6 \%$ para Artes. (Ministerio de Educación. 2010/2011)

Claramente encontramos una jerárquica, donde la cúspide está coronada por las asignaturas racionales, más pragmáticas como las matemática y la ciencia, seguidamente las lenguas y el ámbito social, un paso por atrás las humanidades, y en el fondo las artes. Todos/as los/as estudiantes desde que abandonan la guardería se aleccionan para que sean grandes prodigios en las mismas materias, materias que por importantes que sean, no son únicas, en la vida todo es necesario, y de hecho de la variedad, de la unión de la diversidad de materias nacen resultados de mayor calidad. Actualmente la educación se ha percatado de este problema, e intenta fomentar la cultura emprendedora en los diferentes estamentos de la educación. En Andalucía, este 2011 se aprobó el DECRETO 219/2009,de 28 de junio, por el que se aprueba el Plan para el Fomento de la Cultura Emprendedora en el Sistema Educativo Público de Andalucía (BOJA núm.37, 2011, p.1). Una gran inversión, con vistas a diez años, donde se implantará herramientas y mecanismos para fomentar la creatividad, innovación, responsabilidad y emprendimiento entre el alumnado y el profesorado de los centros educativos. Andalucía comienza a invertir en emprendimiento, alentada por ocupar la primera posición en creación de empresas con filosofía de cultura emprendedora, un 24,8\% (CEPES-Andalucía 2011) de empresas de economía social, con respecto al resto de comunidades españolas.

En los años 50, el deporte en España no recibía ni movía las masas como lo hace en la actualidad, era una práctica rara que la realizaban algunas personas. En los años 70, y gracias al esfuerzo de Joan Antoni Samaranch, gran promotor de la cultura deportiva en España, la asignatura de educación física se incorporó a las escuelas. Al principio la sociedad se quedó extrañada, ¿cómo en un colegio se podía hacer deporte? A las escuelas se va a estudiar, y para aprender no es necesario ponerse en pantalón corto para correr. Este desapego fue transformándose hacia un sentimiento de aceptación hacia la educación física, creando conciencia de la importancia de una cultura deportiva, y según cuenta Jose Manuel Pérez: gracias a ello, la implantación de la asignatura de la educación física en los centros educativos, se llegó a los Juegos Olímpicos de Barcelona 92. Es decir, en aquel momento, de forma consciente, se optó por educar a la sociedad, cambiar su estilo de pensar a través de la educación, animar al mens sana in corpore sano, se impulsó e invirtió en las personas, en los estudiantes, en vez de optar por construir complejos deportivos directamente, los cuales seguramente hubieran quedado despoblados debido a la carencia de una 
chispa de cultura deportiva, instauraron en los centros educativos la asignatura que promocionaba el deporte, y por consiguiente se comenzaba a pensar en la importancia de la cultura deportiva en la sociedad.

La cultura emprendedora, debe seguir este camino, y se comienzan a dar los primeros pasos no solo desde la educación, desde diferentes ámbitos como los concursos y espacios diseñados para fomentar la innovación, creatividad, emprendimiento y responsabilidad:

Podemos llegar al HUB Madrid, espacio para co-crear, perteneciente a la red de HUB de todo el mundo, donde en la actualidad interactúan más de 5.000 emprendedores de 28 ciudades de los 5 continentes. Los HUB, al igual que el espacio EUTOKIA en el País Vasco, ambos son centros de innovación social, donde se apuesta por el capital humano, donde se abraza la innovación y no tiene cabida lo lineal, cotidiano y normal. Pero las personas emprendedoras comienzan a moverse en estos espacios, creando vínculos, nuevas respuestas, plataformas como Ashoka, la primera red mundial de emprendedores sociales innovadores. Tratando temas diferentes como el periodismo, medio ambiente, la educación, la salud o la igualdad de género, buscan encontrar los problemas en estos ámbitos y transformarlos mediante un nuevo enfoque: cultura emprendedora, dar una visión a lo establecido.

Estas fuentes de emprendimiento social, son reductos que cada vez laten con más fuerza en las ciudades. Sin embargo, los/as jóvenes aún no se atreven a dar ese paso, el de crear, el de querer encontrar problemas, puesto que cuando se aporta una nueva visión a un objeto cotidiano, ya establecido, el cambio siempre resulta chocante, pero no por ello significa que estará mal, y si lo está, se intentará de nuevo, y si esta segunda vez también está mal, estaremos creando escuela, sabiendo cómo no hay que hacerlo, porque eso es cultura emprendedora, ser creativo, innovador, responsable y emprendedor.

Este fomento de la cultura emprendedora, necesita estar presente en la vida de los/as jóvenes, de una forma amena y atractiva, que quieran ser emprendedores culturales, sin ser sinónimo de aburrido o ser estigmatizado como un paria. En el estudio Impulsa tu futuro (Tuenti, 2011) realizado por la red social Tuenti a 9.569 jóvenes, 1.897 hombres y 1.032 mujeres, con una edad comprendida entre los 16 y 29 años, respondieron que la principal causa que les impiden comenzar a emprender era la falta de ayuda económica (912 respuestas) muy seguida por la inseguridad o el miedo al fracaso (775respuestas), distando en bastante distancia de la comodidad (511 respuestas), falta de formación (298respuestas), falta de información (256 respuestas) y en último lugar época de crisis (204 respuestas). En el estudio, nos encontramos con que las respuestas que reciben más puntuación son las que hablan de emprender: 1.647 jóvenes tienen ideas, se ven capacitados para montar su negocio; 1.160 opinan que la educación debería replantearse en todos su ámbito, tanto la escolar como la universitaria, propiciando nuevas motivaciones empresariales; 1.784 encuestados/as se ven capacitados/as para crear su empresas y 1.198 se imaginan un futuro donde ellos/as son los que dirigen su negocio, son los/as que toman sus propias decisiones en su trabajo. 
Luisa Alemany, coordinadora del proyecto Libro blanco de la iniciativa emprendedora en España (Alemany, L; Álvarez,C.; y Urbano, D. 2011. p 166), aporta luz al análisis de la cultura emprendedora a través de los siguientes datos:

- Sólo un 5-7\% de las personas en edad de emprender en España son emprendedores.

- En España se decide emprender más por necesidad (un 60\%) que por que han visto una oportunidad para emprender (un 40\%).

- Sólo 2 de cada 10 españoles se consideran creativos.

- Sólo un 12\% de los encuestados consideran que toman riesgos. Este bajo porcentaje se debe al miedo al fracaso.

- Además, 8 de cada 10 de las personas consultadas considera que su vida está determinada por las acciones de otras personas o causas externas.

- Un $48 \%$ piensan que el emprendedor tiene una imagen favorable, pero los jóvenes admiran figuras tópicas como los abogados, médicos, arquitectos, científicos, futbolistas, etc.

Con todo lo expuesto hasta el momento, podemos vislumbrar que falta una rueda para que el engranaje de la cultura emprendedora comience su marcha. Recolectando los problemas encontrados hasta el momento, tenemos que los/as jóvenes, no emprenden por miedo al fracaso, el qué dirán, la opinión de su círculo es de gran importancia para ellos/as, el miedo a poder quedar en ridículo les impiden ser emprendedores. Relacionada con esta premisa encontramos que casi todo lo que les ocurre está condicionado por agentes externos, no se creen poseedores de las riendas de sus vidas, y por tanto creen que el desarrollo de un proyecto depende de muchos factores externos y no de ellos/as. Y el tercer estigma más repetido es la falta de fe en ellos/as mismos/as, no se consideran personas creativas, con capacidad de innovación y por tanto el emprendimiento muere con esta creencia.

Dicho lo anterior, nos encontramos con un problema de auto-confianza, un muro creado e incentivado por la importancia que le damos a la opinión de la sociedad, impidiendo que cada persona se lance al camino de la emprendiduría, perdiendo cada día grandes talentos que podrían haber aportado nuevas visiones e ilusiones a la sociedad que tanto temen.

Una herramienta clave, culpable en cierta medida de la falta de cultura emprendedora, pero que podría utilizarse para solventar estas barreras que poseen los/as jóvenes, la encontramos en la comunicación, comunicación en su pleno sentido, no solo los canales convencionales y no convencionales (Internet, Televisión, Prensa...), también en sus contenidos (programas, series, letras de las canciones...).

Nos encontramos ante una gran variedad de contenidos audiovisuales que estimulan, divierten y consume la juventud española. Todo consumo ocupa protagonismo entre los/as jóvenes, como vehículo irremplazable para conseguir la aceptación en la sociedad y con ello la felicidad. En 2010, según el informe Infoadex 2011, la Inversión Real Estimada que registró el mercado publicitario se situó en un volumen de 12.883,8 millones de euros, lo que representa un crecimiento del $1,4 \%$ sobre los $12.709,0$ 
millones de euros que se alcanzaron en el año anterior. El consumo de medios aumenta, según el estudio 2011 Cisco Connected World Technology Report asegura que el $64 \%$ de los/as estudiantes universitarios/as definen Internet como "parte integral de sus vidas" y para la mitad de estos estudiantes u el $48 \%$ de los jóvenes profesionales españoles la interacción en las redes es considerado como "un recurso vital, como el agua, la comida o la vivienda". Necesitan estar conectados, estar expuestos a los demás. Saber qué opinan sobre ellos, conectados las 24h expresando sus pensamientos y gustos, pero sobre todo esperando la aceptación de los demás.

Por su parte la televisión, continúa siendo el medio rey, los/as españoles pasamos una media de 234 minutos por persona y día (148 minutos los/as jóvenes con edad entre los 13 y 24 años), 44 minutos por encima de la media mundial en consumo de televisión situada en 190 minutos. Si nos centramos en los contenidos, los programas a los que más tiempo se les dedicó atención en 2010 fueron los de ficción (400 minutos), los informativos (291 minutos) y los culturales (206 minutos), coincidiendo exactamente con los mismos programas que tuvieron mayor audiencia, según el estudio Egeda, Paronama Audiovisual 2011. Las tramas de las series televisivas, son adoptadas como representantes de los problemas y rutinas que los/as jóvenes tienen en su día a día, se sienten identificados con la ficción que se les ofrece, y seguramente como transcurra la ficción tomaran nota para aplicarla a su vida.

El consumo de medios de comunicación se convierte en un valor social, transformando y condicionando el carácter de la mayoría de los/as jóvenes, y con ello su comportamiento de emprendedor/a. Nuestro público al que debemos motivar en cultura emprendedora, se encuentra en los medios de comunicación. No es necesario encontrarles, puesto que son ellos los que nos encontrarán y debemos tener una respuesta de calidad para ofrecerles. Los autores Martín y Velarde (2001) establecen dos grupos de consumo juvenil, según el fin que esta acción establece en los/as jóvenes en su transformación hacia la vida adulta:

\section{a) El consumo que cumple funciones relacionadas con la identidad juvenil}

Dicha categoría agrupa los esfuerzos, tanto económicos como sociales que invierten los/as jóvenes para conseguir ser aceptados en su grupo social, tribu, identificándose con otras personas con sus mismo hábitos de consumo de medios, actividades e ideas.

\section{b) El consumo que cumple funciones relacionadas con la incorporación a la vida adulta}

Cada vez más el proceso de emancipación se alarga en el tiempo, debido a la necesidad de recursos por parte de los/as jóvenes mientras se forman y la dificultad en la inclusión laboral, y por tanto retrasando la llegada a la vida adulta, la independencia. Los/as jóvenes, con recursos medios, desembolsan su dinero en tecnología, revistas y periódicos, juegos de azar, vídeos y discos, conciertos musicales, vacaciones con amigos y espectáculos deportivos (Martín y Velarde 2001), una completa inversión hacia la cultura social, otorgándoles el papel protagonista desde la óptica de los medios de comunicación, y estos lo saben. Los estudios que abordan el consumo de medios de información por parte de los/as jóvenes 
Con todo lo anterior, vislumbramos unos jóvenes, con ganas de aprender, pero atados por el miedo a fracasar delante de todo un público social que además interactúa a diario. Por ello, en este escenario es necesario la presente investigación, donde se pretende mostrar la comunicación en todo su potencial, no solo el canal también sus contenidos, como una herramienta del fomento de la cultura emprendedora, puesto que la creatividad, innovación, emprendimiento y responsabilidad impregnan a diario los contenidos de los medios de comunicación: anuncios publicitarios, películas, programas de radio o plataformas de Internet, son algunos de los ejemplos a través de los cuales se debería fomentar la cultura emprendedora, porque nos encontramos en una etapa de reconstrucción de lo conocido, repensar lo establecido, es decir imaginar, crear, y todos debemos ser responsables del cambio, apoyar las ideas, es tiempo para las personas que piensan para personas, es el tiempo de la cultura emprendedora.

El concepto cultura emprendedora ha ido evolucionando con el transcurso del tiempo, decantándose según casa autor hacia un ámbito más empresarial o hacia otro más dinámico y creativo. Desde las instituciones públicas la idea de cultura emprendedora es definida como una competencia basada en la capacidad para provocar cambios y la habilidad para aceptar y apoyar cambios producidos por factores externos (Consejo Europeo de Lisboa, 2000). Está relacionado con la creatividad, la innovación y la asunción de riesgos, así como la habilidad para planificar y gestionar proyectos con el fin de alcanzar objetivos (Parlamento Europeo 2005). Resumiendo el objetivo de los sistema educativo, como es el caso de Andalucía, consiste en la implantación de estructurar y definir un conjunto de competencias, actitudes, aptitudes y prácticas, para desarrollar la cultura emprendedora en las enseñanzas de Educación Primaria, Educación Secundaria Obligatoria, Bachillerato, Formación Profesional y de las Universidades Públicas de Andalucía, con el fin de aumentar a medio plazo la actividad emprendedora en su más amplio sentido (BOJA núm. 137, 2011, p.4).

Al abordar la temática de la cultura emprendedora para la realización de este proyecto, se ha podido comprobar cómo una parte de los estudios, artículos y documentos existentes sobre cultura emprendedora van enfocados hacia la economía, pretendiendo estudiar a empresas que pongan de manifiesto la relación entre los conocimientos de los trabajadores y sobre la innovación de las mismas (Pizarro Moreno, I.; Real, J.; De La Rosa, Ma. D. 2010). Docentes y autores sobre cultura emprendedora (Rodríguez y Delgado, 2010) resaltan en los contenidos que imparten, la importancia de los tipos de empresas, formas jurídicas, plan de empresa y contabilidad, más que la filosfía que implica la iniciativa emprendedora. Esta línea ha seguido extendida por instituciones como la Comisión Europea en el Libro Verde "El espíritu empresarial en Europa" (2003), donde se destaca el espíritu emprendedor y empresarial como motor principal de la innovación, la competitividad y el crecimiento europeo, otorgando a la figura del emprendedor a ser desarrollar la economía europea. Semejante es la idea que obtenemos de "El emprendedor nade o se hace" (2005) o Plan de acción "El programa europeo en favor del espíritu empresarial" (2004) donde se enfoca la cultura emprendedora como una fábrica de generar 
personas motivadas para ser empresarias, basándose en la importancia de los factores externos que rodea a la persona como camino hacia la gloria.

Pese a este difuminado enfoque, cada vez son más las miradas situadas en la cultura emprendedora como uno de los principales impulsores de la innovación, la competitividad y el desarrollo económico y social (Carree y Thurik, 2003; 2005; Wennekers y Thurik, 1999). Es decir esta renovada corriente de pensamiento refuerza la idea en la creación de oportunidades (Kirzner, 1979), otros piensan en el diseño y estructura de yacimiento de nuevas empresas (Gartner, 1985) o en la creación de proyectos innovadores (Casson, 1982). También se debe recordar, que la cultura emprendedora no implica la creación de una empresa, aunque se incluya en dicho proceso, también cabe la posibilidad de innovar una entidad que ya exista, cambiar su filosofía empresarial actual por la de emprendimiento cultural (Miles y Covin, 2007).

La realidad es que se está cambiando, la sociedad ha despertado debido a que su entorno se tambalea y se despierta en busca de soluciones, unas soluciones que vienen de la mano de la innovación en la utilización de los recursos de los que se dispone (pocos o muchos) para conseguir una solución (Mair y Martí, 2006).

La creación de un fin social, estructurar una nueva filosofía basada en la adaptación de las materias que tenemos a nuestro alcance potenciándolas con la creatividad y sabiendo correr qué tipos de riesgos, son las características de las personas emprendedoras que se lanzan a este viaje hacia la innovación social (Perede y Mclean, 2006).

Estas características se verán desarrolladas en los centros educativos a todos los niveles, potenciando las competencias y habilidades de los/as estudiantes, pero nuevos centros innovadores, con nuevas asignaturas y pensamiento en su funcionamiento, primando la promoción de las habilidades de los alumnos (Kirby, 2006), más que la de estudiar por estudiar. Así lo promocionan los organismos públicos, donde marcan como objetivos futuros de los sistemas educativos, el refuerzo de los vínculos entre instituciones educativas y empresas, así como el desarrollo del espíritu de empresa en la educación y en la formación (Consejo de Ministros de Educación de la UE, 2001). Esta actitud queda reflejada en la Carta de Bolonia, firmada en la Primera Conferencia de Ministros Responsables de Pequeña y Mediana Empresa (2000) donde se establece un mecanismo de reconocimiento europeo de titulaciones basado en la calidad, incorporando otros valores como el fomento de la cultura.

Los primeros antecedentes en formación sobre emprendimiento fueron impartidos por Miles Mace en Harvard Business School en 1947 y por Peter Drucker en la Universidad de Nueva York en 1953 (Brockhaus, 2001). Ya en la década de los años '80 alrededor de 300 universidades ofertaban cursos relacionados con la iniciativa emprendedora, ascendiendo esta cifra a 1.050 en los años '90 (Kuratko, 2005).

A lo largo de la historia encontramos diferentes propuestas para aprender la cultura emprendedora, aportar por la protección de ideas (Vesper y McMullan, 1988); el 
conocimiento del emprendimiento como opción de carrera profesional (Hills, 1988); características asociadas a la personalidad emprendedora (Hills, 1988; Scott y Twomey, 1988); cambios asociados a cada etapa del desarrollo de la nueva empresa (McMullan y Long, 1987; Plaschka y Welsch, 1990); gestión del plan de negocios (Gartner y Vesper, 1994; Gorman et al., 1997; Hills, 1998; Vesper y McMullen, 1988); creación de empresas (Hills, 1988); consultas y entrevistas con personas emprendedoras; (Clouse, 1990); simulaciones basadas en la tecnología (Hindle, 2002); influencia de los videojuegos de rol (Robertson y Collins, 2003); aprendizaje experiencial (Sexton y Upton, 1987); y exploración del entorno (Solomon et al., 1994). Autores como Vesper y McMullen (1988) invitan a involucrar facetas de líder, pensamiento imaginativo y nuevas formas en el uso de las tecnologías en el aprendizaje de la cultura emprendedora.

Pese al esfuerzo por insertar la cultura emprendedora en la educación, existen algunas dificultades, como la falta de coordinación con la educación informal: familia, entorno y medios de comunicación (Ministerio de Educación y Ciencia, 2006), haciendo que la transmisión del pensamiento de emprendimiento cultural no se logre. Por tanto la educación no es la única impulsora en el proceso socializador de los jóvenes en emprendimiento cultural, las industrias culturales desempeñan el rol de diseñar y producir contenidos, difundiendo y consolidando una legitimación de estereotipos y valores (Jones y Thornton, 2005), descubriendo en la relación entre medios de comunicación y cultura emprendedora un buena sinergia para su fomento.

En El libro Blanco de la Cultura emprendedora (Alemany, L; Álvarez,C.; y Urbano,D. 2011), cuyo objetivo era identificar los factores más importantes en el fomento del espíritu emprendedor entre los/as jóvenes de España, sentencian en sus conclusiones: ser empresario es una buena opción profesional, sin embargo los medios de comunicación podrían colaborar más en el fomento de la cultura emprendedora (2011, p 166).

\section{METODOLOGÍA}

Para poder realizar el presente trabajo se han aplicado técnicas metodológicas de diferentes estilos, dependiendo de la información que se necesitaba extraer para responder a las preguntas realizadas por el trabajo. Sumado al estudio de fuentes secundarias relacionadas con los medios de comunicación, cultura emprendedora y hábitos de jóvenes, la técnica principal que nos ha llevado a las conclusiones de este trabajo ha sido la técnica cualitativa denominada entrevista en profundidad a informantes claves de diferentes ámbitos relacionados con la sociedad, educación, emprendimiento y los medios de comunicación. Las entrevistas se han realizado de manera individual, enfocadas al tema de la cultura emprendedora y los medios de comunicación, dando lugar a una entrevista con preguntas abiertas, permitiendo al entrevistado/a profundizar en las respuestas y exponiendo sus conocimientos de la manera más sincera y subjetiva posible.

El proceso estructurado de la entrevista en profundidad que se ha llevado a cabo ha sido el siguiente (Ruíz, J.I. 2007): 
1. Elección del informante.

2. Acceso al informante

3. Preparación de la entrevista.

4. Realización de la conversación.

5. Transcripción.

El cuestionario realizado está compuesto por diez preguntas clave, en el marco de la siguiente estructura de la entrevista:

1. Interacción entre el/la entrevistado/ay el entrevistador:

- Presentación del entrevistador.

- Motivo de la entrevista. Justificación del proyecto. (Anexo 1)

- Condiciones de la entrevista: grabación de la misma.

2. Recogida de la información respondida.

- Preguntas de carácter general.

- Preguntas centradas en la relación de la comunicación y la cultura emprendedora.

3. Registro de la información: vídeo - grabación de audio.

La selección de los/as informantes clave se ha llevado cabo por su relación con la comunicación y con la cultura emprendedora, por consiguiente los cuatro apoyos que la describen: la creatividad, innovación, emprendimiento, responsabilidad. Las personas elegidas forman parte del mundo académico y/o profesional, del ámbito de la comunicación y del sector creativo-cultural. A continuación podrán leer una reseña de las ocho personas entrevistadas en este proyecto:

\section{ALICIA MURILLO}

Coordinadora Provincial del Instituto Andaluz de la Juventud en Málaga.

Licenciada en Administración y Dirección de Empresas por la Universidad de Málaga, y empleada de la entidad financiera Unicaja.

\section{DAVID LÓPEZ MEJUTO}

Formador de menores, adolescentes y adultos. Posee formación en el ámbito de la intervención psicológica y la educación. De su trayectoria profesional destaca su trabajo como psicólogo en escuelas de padres y madres en diferentes colegios de Sevilla, la dinamización comunitaria, la mediación intercultural y la coordinación de proyectos de ocio constructivo, así como su experiencia como orientador laboral en el Programa Andalucía Orienta. En la actualidad se encuentra en proceso de formación en Terapia Gestalt. Autor del material: "SOÑAR CANTANDO" www.psicolopezmejuto.com. Licenciado en Psicología por la Universidad de Sevilla y Colegiado por el Colegio Oficial de Psicólogos. Máster en Intervención Psicológica.

\section{DIANA NAVARRO}

Cantante española dedicada a su profesión durante quince años en géneros como copla, pop y canción de autor plasmados en cuatro discos y diferentes trabajos donde ha colaborado. Tiene en su haber un disco de oro, un disco de platino, premio Ondas al artista revelación, una nominación a los Grammy Latinos en la misma categoría, dos Premios de la Música (concedidos por la Academia de las 
Artes y las Ciencias de la Música de España). La artista malagueña a llevado su voz al ámbito internacional actuando en ciudades como Nueva York, Washington, Miami, Londres y Paris.

\section{FERNANDO FANTOVA. Viceconsejero de Asuntos Sociales.}

Director de la Fundación Vasca para la Innovación Sociosanitaria.

Doctor en Ciencias Políticas y Sociología. Licenciado en Psicología. Educador Social.

JONAY SOSA. Copywriter en la sede de Madrid de la agencia de publicidad internacional Saatchi \& Saatchi. Realiza anuncios publicitarios para marcas comerciales nacionales e internacionales. Elaborando y transmitiendo de la mejor forma posible el mensaje que deben recibir los receptores por parte de la marca.

Licenciado en Publicidad y RRPP por la Universidad de Málaga.

JOSÉ MARÍA GASALLA. Presidente del Grupo "Desarrollo Organizacional" y de "Talentum". Director del Programa "Gestión del Talento" de ESADE. Evaluador del proceso de acreditación de coachs profesionales, senior y coachs ejecutivos de AECOP (Asociación Española de Coaching). Consultor internacional y consejero de empresas (como Telefónica, BBVA, Coca Cola, IBM, Zara, etc) en el área de cambio y desarrollo de las organizaciones. Autor de "Confianza y compromiso", "Quien lidera confia", "La nueva dirección de personas: Talento", "Marketing de la formación de directivos". Ingeniero Aeronáutico, Doctor en C. Económicas y Empresariales, Diploma de Estudios Avanzados en Psicología Social.

ROCÍO GARCÍA SAN MIGUEL. Manager en Warner Music Spain, donde trabaja en el departamento de promoción, convirtiéndose en intermediaria entre el/la artista y los medios de comunicación en cuanto, permitiéndole conocer de primer orden lo que buscan tanto los artistas, la empresa así como el público, para realizar diferentes acciones de comunicación. Licenciada en Publicidad y RRPP por la Universidad Complutense de Madrid.

SUSANA HERRERO. Propulsora del Plan Integra, servicio de asesoramiento emprensarial para jóvenes emprendedores que incluyen sesiones personalizadas de coaching, formación específica sobre creación y consolidación de empresas y un espacio gratuito para la ubicación de la empresa. Técnica de autoempleo en el Instituto Andaluz de la Juventud, responsable del área de autoempleo en la Asociación Arrabal-AID, donde orienta, gestiona y promueve el trabajo propio, la creación de empresas o proyectos sociales. Licenciada en Derecho por la Universidad de Málaga. Máster Experta Unión Europea.

\section{ANÁLISIS Y DISCUSIÓN}

La cultura emprendedora es innata, todas las personas la tenemos y hay que desarrollarla con el paso del tiempo, en muchas personas no se fomenta esta capacidad. La cultura emprendedora significa las ganas de crear algo, creer en un proyecto, a través del cual las personas se sienten realizadas, y por consecuencia, si yo me siento a gusto con lo que desempeño, he conseguido mi propósito, y la 
repercusión será animar y apoyar al resto de la sociedad para que consiga esta misma sensación.

Todo el mundo es emprendedor, es una manera natural de aprender. Cuando somos pequeños, nuestro proceso de aprendizaje es creativa no es racional, el idioma nativo que aprendemos, no nos van enseñando ni explicando a decir "mama, sustantivo común" o "guapa, adjetivo", si no que a un objeto le dicen "zapato" a otro "mesa" y vamos enlazándolo, creando errores de los cuales aprendemos que el objeto "zapato" no se le puede decir "mesa", es decir creando nuevas conexiones y generándonos una visión del mundo en el que vivo. Sin embargo, con el paso del tiempo, dependiendo de nuestra valentía y la atención hacia la presión del entorno vamos viendo que ser curioso puede tener consecuencias negativas, con lo cual dejaré de ser curioso, evitaré arriesgarme a hacer cosas creativas para adaptarme al entorno.

La cultura emprendedora es algo primordial para el ser humano, no se le puede ofrecer nada nuevo al ser humano sin tener una cultura emprendedora. Todos somos buenos desde el nacimiento en alguna o varias facetas, encontrar a las personas o las herramientas adecuadas para desarrollarlo es un punto fundamental, prueba de ello es el cambio de sistemas educativos, muchos niños/as tienen problemas porque no se adaptan a la educación común y necesitan una atención diferente al resto.

En una educación jerárquica donde en la cima de la pirámide nos encontramos las matemáticas e idiomas, seguido de las ciencias sociales, sin lugar alguno para cualquier tipo de arte ni recreación y mejora de la creatividad humana, por lo que se está consiguiendo matar muchas ideas, anteponiendo fórmulas y datos, que si son correctas se mantendrán por siempre en la historia, a las ideas que se generan según el contexto y su relación cada persona únicamente en ese instante de la historia. Prestemos atención a toda la innovación que estamos dejando dormida en los/as jóvenes.

La cultura emprendedora, es totalmente transversal a todas las materias, con lo cual estaríamos eliminando esa jerarquía de importancia en las materias, cuanto más aprendamos y mezclemos materias, mejores soluciones obtendremos. En la historia de la evolución, aquellos que aprendieron a colaborar y a improvisar de manera más colectiva han prevalecido (Charles Darwin), es decir los que no han aprendido a improvisar o a colaborad de una forma activa, colaborativa han desaparecido.

Borja Baturone, experto en gestión de la innovación, comenta en la jornada Compromiso con las personas. Innovación en las organizaciones organizada por ICONG en Madrid, un claro ejemplo de conexión de dos ámbitos diferentes:

"Un estudio farmacéutico pretendía encontrar nuevos tratamientos para aliviar el dolor a través de la creación de un medicamento. Lo que hicimos fue traer a las sesiones líders master de sesiones sadomasoquistas ipor qué? Porque estas personas enseñaron a las personas de bata blanca que el dolor es subjetivo, compartieron que existen diferentes grados de subjetividad en la comprensión del dolor, como pueden 
controlarlo e incluso transformarlo en placer, pues los aprendizajes para los investigadores de la farmacéutica fueron brutales".

Cuanto más nos alejemos del mundo conocido y más podamos inspirarnos en nuevos parajes desconocidos a lo que hacemos, obtendremos más variedad y por consiguiente más respuestas totalmente diferentes. Improvisar sobre alguna materia, requiere ser consciente del entorno en el que vas a desarrollar, y hoy día las personas achacan a la difícil situación económica la causa de su falta de emprendimiento. Sin embargo, la crisis económica ya pasó, lo que estamos viviendo es una etapa diferente, una etapa de desconcierto donde es necesario crear y emprender nuevos caminos, porque los establecidos ya los agotamos, les estrujamos demasiado y nos derivaron a la crisis comentada. Es por esta razón, que el estado actual, la crisis supera a muchas personas, porque nuestra mente no está habituada a las situaciones de cambios. El principal cambio, en el sistema actual lo encontramos en la confianza, actualmente las personas, y sobre todo los/as jóvenes no le otorgan credibilidad al sistema que les ha formado, un sistema que les prometía un futuro estable, si seguían los pasos que les dictaban en la formación, porque si te salías del camino marcado, si no estudiabas lo que el sistema te había puesto sobre la mesa como lo necesario para trabajar no tendrías futuro. Los/as jóvenes cumplieron con su parte del trato, aprobaron la E.S.O (Educación Secundaria Obligatoria), seguidamente Bachiller, se prepararon la prueba de acceso a la Universidad y finalmente consiguieron una carrera, todo ello aderezado con cursos de idiomas y congresos, para finalmente no obtener una red de seguridad que pare su caída el desempleo. Tienen derecho a sentirse desconfiados.

Pero ¿por qué no confiamos? El ser humano cuando comienza a confiar en alguien o algo, desconecta sus barreras, es decir se vuelve más vulnerable, porque confía en un objeto que le va a tener a asegurada un ámbito de su vida. Cuando esta confianza se ve fragmentada porque el objeto en el cual confiabas no cumplió tus expectativas, no solo lleva al sujeto a un estado de decepción, si no que crea en él la desconfianza para creer en otra cosa. El actual sistema financiero la describe Jose María Gasalla, como la falta de confianza, los bancos no confían en los mercados, las personas no consumen porque no se confían de que puedan tener trabajo durante mucho tiempo, y si no se consume las empresas no invierten porque no confían en la actitud de los consumidores, con lo cual estamos inmersos en un sistema con clima de desconfianza. Y seguidamente esta situación se está expandiendo hacia el sistema educativo, porque la confianza que los jóvenes depositaron en el, no les está sirviendo en la actualidad para crear soluciones ¿por qué? Porque no les enseñaron a ser innovadores, creativos, a arriesgarse, a ser emprendedores, en el sistema educativo en el que se formaron les dieron respuestas para estudiar no la herramienta para saber crearlas, no había cultura emprendedora.

Sin embargo la confianza igual que se pierde se puede volver a conseguir, pero no es una tarea fácil porque las personas mostrarán reticencias. José María Gasalla, comenta la siguiente ecuación para conseguir aumentar la confianza:

$$
\text { Conf } \times \text { Cont }=\text { Cons }
$$


La confianza por el control es igual a constancia. Si tu logras aumentar la confianza en un sistema puedes disminuir el control, no necesitas tenerlo vigilado, para que siga siendo constante, esta fórmula nos dice que cualquier fe es mayor que cero. Creer en lo que hace los demás, comprobar que funciona la cultura emprendedora, me otorgará confianza para comenzar a seguir el mismo camino.

La ejemplaridad de lo cercano, es la base para la confianza. Y una vez que generamos confianza, seguidamente entre el juego el factor de la automotivación, confías en ti mismo como principal responsable para trabajar en tu proyecto, de una forma constante, aceptando riesgos para obtener tu meta. En el sistema educativo se ha promovido la motivación de los/as jóvenes: si estudias, si llegas a la universidad tendrás un puesto de trabajo seguro. Pero la motivación es perjudicial, porque no fomenta nuestra automotivación, es decir, si el sistema me motiva a realizar algo, lo acabaré haciendo porque me están animando a realizarlo, pero ¿me identifico con lo que estoy haciendo? Si esta motivación externa cesase, mi automotivación, mi fe en lo que hago ¿me permitiría continuar felizmente con mi tarea? La respuesta sería que continuaríamos con ello, pese a nuestros sentimientos, porque nos han enseñado a que hay que seguir los patrones establecidos. La autoconfianza es importante en el fin que no podemos inspirar confianza a otras personas si uno no cree en sí mismo.

Las personas confiamos en otras, con lo cual no solo debemos pedir confianza, también debemos de dar confianza. Una gran nube que planea sobre la juventud actual es la falta de compromiso hacia el desarrollo de algún proyecto, bien sea laboral, social o personal. ¿Pero qué se hace para que los jóvenes se quieran comprometer? En el ámbito laboral no hablamos de fijarle en un puesto de trabajo para toda la vida, comenta Jose María Gasalla, sino de la creación de un espacio de confianza donde el joven empleado o empleada pudiera ser cada vez más él/ella mismo/a y pudiera capitalizarse como profesional, y por lo tanto cada vez más empleable, aumentando su confianza no solo en sí mismo, si no en la labor desempeñada, porque lo que esté trabajando lo considerará importante porque le permite crecer como profesional, es decir sentirse que aprovecha lo que hace, sin estar en la posición estanca de un puesto de trabajo que desarrolle la misma función todo el tiempo. Si las empresas ofrecieran a los/as jóvenes este tipo de compromisos, puestos donde cada uno/a pudiera no solo hacer su trabajo si no ser creativo, innovador, poder arriesgarse, ser emprendedor, los/as jóvenes seguramente se comprometieran con las entidades. En el momento que dejemos de desconfiar, obtendremos sistemas más abiertos, que permitan a cada persona, proyecto o entidad poder desarrollarse.

En la manera más práctica, la cultura emprendedora es una opción que los/as jóvenes desconocen para incorporarse al mercado laboral: crear su propio empleo. Están informados y animados a la única opción de incorporarse al mercado de trabajo a través de la contratación por parte de una empresa. Es la posibilidad que todas las personas tenemos de crear nuestro propio empleo, además, con la calidad y condiciones que nosotros mismos queremos. 
Si analizamos la vida social, política y económica descubrimos muchas organizaciones y entidades exitosas que lo han logrado gracias a una primera idea que les llevó a ser exitosa, y en un primer momento resultó ser chocante cuando la propusieron. Toda nueva idea suele ocurrir que al principio es ignorada, luego es combatida y luego es asumida como lo más normal del mundo, comenta Fernando Fantova, Doctor en ciencias políticas y sociales. La persona creativa, innovadora, tiene que tener claro que va a tener una resistencia del entorno. Los ejemplos de personas emprendedoras consolidadas nos dicen, recuerden el ejemplo de Bart en la introducción de este trabajo, que son personas que se salen de los moldes, que se salen de la cuadrícula, de los cánones establecidos, pero que gracias a su constancia se crean nuevas y mejores soluciones pese a la falta de apoyo del entorno que les rodea.

Cuando pensamos sobre personas emprendedoras, nos vienen a la mente varios ejemplos, y ejemplos que aunque no sean conocidos popularmente, les tenemos un gran respeto, les procesamos una admiración hacia su trabajo y los tenemos como referentes de personas que han sabido salirse de lo establecido y crear su lugar en el mundo.

\subsection{Perfil de la persona emprendedora: dando la cara.}

Un emprendedor o emprendedora debe tener una actitud de búsqueda, avanzar hacia lo desconocido, querer siempre aprender, conocer lo oculto, sin miedo a descubrirlo, y como transmite David López Mejuto, la capacidad de anticiparse a los hechos, así como un imprescindible "espíritu soñador". En definitiva buscarse problemas, detectar las necesidades de su entorno para solucionarlos. Los principales obstáculos a la iniciativa emprendedora son la falta de ayudas económicas, la época de crisis, la inseguridad y el miedo al fracaso (Alemany 2011).

Cuestionarse lo establecido es una ardua tarea, a la que pocos se entregan encarecidamente, puesto que en la mayoría de los casos contamos con las opiniones dubitativas de familiares y amigos/as con respecto a la búsqueda de problemas, o lo que es lo mismo otorgar un nueva visión mejorada a lo ya establecido. Pero cuando esto sucede, cuando una solución nueva y con buenas expectativas es creada por alguien, el resto de personas llegan en algunas ocasiones a sentirse desafortunados, y por tanto cultivando un sentimiento de envidia hacia la persona emprendedora, lo que se traduce en un rechazo hacia esta actitud de buscar, crear nuevas soluciones, y la retirada del apoyo hacia la actitud emprendedora.

Según datos del Eurobarómetro 283, los/as jóvenes españoles prefieren un puesto de trabajo por la estabilidad que les proporciona (52\%) además de obtener un ingreso fijo $(38 \%)$, estar cubiertos con seguridad social $(21 \%)$ y mantener un horario de trabajo establecido (19\%). Frente a estos porcentajes nos encontramos con un $74 \%$ que se posicionan en el autoempleo pero justificada por la independencia que les otorga y únicamente un $6 \%$ crearía su propia idea de empresa para aprovechar una oportunidad de negocio. 
Esta actitud emprendedora, puede dirigirse hacia diferentes finalidades que la persona pueda perseguir con la creación de un proyecto. Según el Plan de Fomento de la Cultura Emprendedora (BOJA núm. 137, 2011 p.8) existen tres modalidades de emprendimiento:

1. Emprendimiento personal: proyecto personal, iniciativas para el propio proceso vital de la persona.

2. Emprendimiento social: nuevas iniciativas sociales, mejora de la sociedad y el bienestar común.

3. Emprendimiento productivo: nuevas empresas, creación de riqueza e iniciativas para el progreso económico.

Con estos tres ejes, se crea una base para apoyar la iniciativa empresarial, la optimización y mejora del capital humano y las condiciones de un facilitador de la innovación, competitividad y el valor salarial añadido, para reforzar e incentivar a la persona con ánimo emprendedor.

Las personas emprendedoras, son seres humanos como cualquier otro, que han sabido cultivar su elemento (Robinson, K. 2009), han trabajado en aquello con lo que se sentían cómodo y se les daba bien, sin importarles el valor económico como único fin. El perfil de la persona emprendedora, analiza su entorno, examina las herramientas con las que cuentas y trata de sacarles el mayor partido posible, asumiendo unos riesgos controlados, porque el emprendimiento necesita de responsabilidad a la par que innovación. Este tipo de personas ven los errores como una respuesta, una solución de cómo no se debe crear algo, y no como una señal para abandonar el proyecto sobre el que están trabajando.

En España, existe una gran brecha entre jóvenes emprendedores y no emprendedores. Por una parte nos encontramos un gran grupo de jóvenes que no se destaca por su capacidad emprendedora, por no salirse de los raíles marcados, tendiendo a seguir las rutas que ya están marcadas, y por consiguiente las más fáciles. Nunca se han planteado el emprendimiento como una vía a su futuro sociolaboral, se conforman con formarse, conseguir un título y trabajar para una empresa. En general es normal y esperable que la mayoría de estos jóvenes se apoyen en lo convencional y rutinario, pero eso no quita que no debamos de cambiar este pensamiento e invitar a este grupo a cambiarse al lado de los jóvenes emprendedores, que con cautela y constancia van aumentando su número. Estas jóvenes promesas han descubierto que siendo emprendedores pueden llevar un proyecto de vida que les hace feliz. La felicidad, la pasión, es el verdadero espíritu emprendedor, aquel que capacita a la persona para emprender por gusto, se mueve por la pasión hacia su proyecto, por la fe que tiene hacia la materialización de sus ideas, sin importar el estado de la coyuntura económica. En los tiempos actuales, la crisis económica mundial a forzado a algunas personas a florecer su cultura emprendedora, pero esta cultura originada desde la necesidad normalmente suele marchitarse con el tiempo, puesto que los/as emprendedores/as buscan soluciones rápidas e impactantes para obtener beneficios rápidamente, entrando en una espiral de explotación de los recursos de la nueva idea, quitándole el oxígeno que necesita para continuar brillando y no se apague. 
El éxito es muy relativo, las personas deben ponerse metas reales, no se trata de lo material, si no de lo que de verdad nos completa como persona. En esta línea, suele confundirse a las personas que tienen éxito con empresarios, y una persona emprendedora no es sinónimo de ser empresario/a. El carácter emprendedor apoya la idea de que el éxito se consigue por el trabajo de cada uno, independientemente de la suerte o cualquier factor externo onírico en el que se crea. Cuando la inspiración baje, que me pille trabajando (Picasso, pintor).

\subsection{La ilusión crea empleo, el empleo deshace las ilusiones}

Energía, ilusión, entusiasmo, estás son las características de los/as jóvenes emprendedores. Obviamente la generalización es absurda, hay jóvenes que esperan que por suerte divina el empleo llegue a su puerta, pero cada vez son más los/as jóvenes que se lían la manta a la cabeza fomentando proyectos sociales y no sociales, y lo he podido comprobar en La Feria de la Persona Emprendedora en Valencia (noviembre 2011), y allí vi a miles de jóvenes, y yo confío en ese futuro, comenta José María Gasalla, coach profesional. La juventud española está ilusionada, saben que se encuentran inmersos en una época de cambios, y aprovechan estas circunstancias para formarse y aportar nuevas ideas y proyectos, aunque con cautela, por la falta de aceptación del resto de la sociedad a lo innovador y por consiguiente, estando presente como freno en la mente del emprendedor/a la sombra al fracaso.

Sin embargo, con el sistema educativo actual, el desarrollo de la cultura emprendedora es nulo. En nuestro país, la mayoría de los/as estudiantes estudian para ser trabajadores, convertirse en funcionarios. Los/as universitarios/as, comenta Alicia Murillo, Coordinadora provincial en Málaga del IAJ, en la entrevista, se proponen como meta conseguir un puesto de trabajo donde se les presenten unas condiciones, un sueldo y un horario, y este resultado es todo lo contrario al espíritu emprendedor.

Hay oscuridad en muchos aspectos: sociedad consumista, sistema que no funciona, hay mucha persona que necesita volver a esa luz, y buscar una vía alternativa. El desarraigo está instaurado en muchas personas, y estas personas buscan y finalmente encuentran a otras personas faltan de ilusión creando grandes borrascas de desilusión sobre el resto de personas que aún conservan algo de ilusión. Estas personas que se hunden en la desolación, por norma, suelen pensar que lo que les está ocurriendo no es culpa suya, son víctimas de agentes externos que les hacen que su vida sea peor y por reacción a este pensamiento no hacen nada para modificar su situación. Pero si únicamente se dedicaran a autocompadecerse, pues los podríamos controlar, sin embargo las personas victimistas, se mueven como un viral, creando envidia y recelos hacia las personas que intentan emprender por ser libres de las cadenas establecidas, es decir, ser emprendedor se puede percibir como una carga que conlleve agobios y miedos, y esa responsabilidad como no todo el mundo está capacitado o motivado para alcanzar esa actitud emprendedora, puede generar un cierto rechazo hacia las personas que si la tienen, Rocío García San Miguel, manager Warner Brothers Music. Los/as desilusionados/as creen que las circunstancias les han llevado hasta este fatal destino sin tener nada que ver ellos/as en el trayecto. Están equivocados/as porque cada uno/a de nosotros/as somos responsables de nuestros actos, podremos culpar 
que nos enseñaron mal a doblar una camiseta y por eso está arrugada, pero soy yo quien puede decidir innovar e idear un nuevo modelo para doblar camisetas y no llevarla por más tiempo arrugada. En el momento que tenemos ilusión por algo, surge la creatividad, esa creatividad que nos otorga una pasión descomunal por lo que desempeñamos, una ilusión colosal que nos hace olvidar incluso el tiempo y el espacio en el que estamos, porque queremos absolutamente dedicarnos a sacar adelante nuestro proyecto, o acabar esa novela que con tanta satisfacción hemos comenzado a leer.

La ilusión es el combustible de la persona emprendedora. Un recurso inagotable que debemos usar y compartir, transmitir el gen emprendedor a través de nuestro ejemplo emprendedor, así conseguiremos germinar la ilusión de nuevo en las personas que se habían vuelto ateas de la innovación. Cuantas más personas ilusionadas existan, más conexiones habrá, puesto que una persona ilusionada, busca ir hacia otro ámbitos para crear nuevas posibilidades y oportunidades.

De esta forma, las personas abanderadas de la cultura emprendedora, podrían ser un importante think tank en la inserción de esta filosofía en la sociedad. Los think tank, se definen como entidades que, a través de la investigación y el análisis, proponen propuestas de actuación política a los órganos institucionales mediante estrategias de comunicación directa o indirecta (Castillo, A). Además, del mismo modo que se pretende relacionar en este trabajo la cultura emprendedora con los medios de comunicación, encontramos que el canal más importante usado por los thinks tank para difundir sus mensajes es a través de los medios de comunicación, actuando como intermediarios entre los propios grupos difusores de la idea, la sociedad y las instituciones (Beneitez, M).

Por ello los Centros de Innovación Social, que hemos comentado en la introducción de este proyecto, diseñan espacios diáfanos, donde profesionales de diferentes ramas trabajan con la posibilidad de conversar con otros profesionales de áreas diferentes a las suyas, es decir estos espacios propician la convergencia de personas con cultura emprendedora para posibilitar una conexión de actitudes y con ello nuevas ideas y apoyo mutuo. Pero los espacios sin dinamización, hacen que el proceso de expandir el pensamiento emprendedor sea más lento. Desde los organismos públicos se han llevado a cabo acciones para agitar a los/as emprendedores/as, actividades como proyecto Carabela, iniciativa Emprender en mi escuela, los programas Icaro, Jóvenes emprendedores solidarios, Empresa joven europea, Emprende Joven, Concurso de empresas virtuales, Creando empresas, Emprender en Europa, programa SEFED, simulación de empresas con fines educativos, Music Hero o Emprende tu reto, son algunos de los ejemplos que se han adoptado en las Universidad de Andalucía para despertar el carácter emprendedor aletargado (BOJA núm. 137, 2011 p.4).

Pese a las diferentes actividades, tanto con presupuesto público como privado, que pretenden incentivar la cultura emprendedora, en la concepción que nos han enseñado a actuar, un ámbito operacional, no hay lugar donde albergar la ilusión. Un día a día basado en actividades repetidas, rutinarias, donde en el momento que surge 
la necesidad de buscar una nueva solución, bien por modificar una actividad o por querer adaptar o adaptarme a un nuevo entorno, nos surgen mil dudas y nos sentimos perdidos/as al no saber cómo crear nuevas oportunidades, es decir cómo ser creativos/as. Por más que pensemos, no conseguimos otorgar una respuesta, porque en este ámbito operacional siempre contamos con las mismas herramientas: miro, evalúo y rápidamente decido, y como en este ámbito evitamos los riesgos por el miedo a fracasar frente al resto, nos decidimos por la opción menos arriesgada, la más fácil y por tanto común. La cultura predominante presenta rasgos que no favorecen al espíritu emprendedor, normas sociales y culturales pocas propicias al emprendimiento, con ninguna tolerancia al fracaso y poca predisposición a considerarlo un factor u oportunidad de aprendizaje, resistencia al cambio innovador (BOJA núm. 137, 2011, p.5). Por suerte, la cultura emprendedora invita a trabajar en el ámbito de la innovación, un campo repleto de procesos, como en el operacional, pero diseñado para fomentar la creatividad y no a implantar la creación. Si una idea no parece absurda, no hay lugar para ella (Albert Einstein) porque si es verdaderamente nueva una idea no debe encajar, debe ser completamente distinta, la vemos imperfecta porque nos choca con las referencias que hasta ahora conocemos. Ideas comprometidas, que nos comprometan ese es el camino, porque la emoción y el amor es el motor que te ayuda a sentirte bien y sentirte fuerte para hacer cosas diferentes y emprendedoras. Elegido el ámbito donde nos reconforta crecer como profesionales y personas, debemos ser innovadores. La innovación es creatividad implantada con éxito, otorgando una nueva visión sobre algo, porque si no está aceptado por la sociedad, tenemos solamente algo nuevo, tenemos solo ideas que no podrán materializarse y por tanto se desvanecerán en el tiempo.

\subsection{El plan de comunicación para la cultura emprendedora.}

La cultura emprendedora necesita promocionarse desde la escuela, institutos, universidades pero con el apoyo de los medios de comunicación, entre todos los involucrados debemos crear un plan de comunicación para el fomento de la cultura emprendedora. Desde que somos pequeños/as se nos alecciona para que estudiemos aquello que estudian los demás, conquistar las mismas metas que el resto de personas que estudian paralelamente con nosotros/as. Los núcleos familiares son frenos que retrasan el desarrollo de la cultura emprendedora. Si recordamos el caso que comentábamos al inicio de este proyecto, Bart era un niño que andaba sobre sus manos, y si su madre no hubiera potenciado esa peculiaridad, habría obligado a Bart a que dejara de realizar esa "absurda" actividad, y se pusiera a estudiar "que es lo que verdaderamente importa". Este pensamiento es el que cada día se va gestando en la mente de los/as emprendedores/as del mañana, se coarta su creatividad y por consiguiente la innovación hacia el emprendimiento. Por tanto es necesario que cambie el sistema educativo, y lo apoye una figura amiga de los jóvenes, que son los medios de comunicación, que nos animen a inventar y a crear nuevas condiciones. Los expertos afirman que la educación no fomenta actitudes emprendedoras, no desarrolla ni impulsa competencias emprendedoras y que el entorno familiar de los/as jóvenes no incentiva el pensamiento crítico y la autoestima (Alemany 2011). 
Los medios de comunicación están presentes en la vida de las personas. En España el $99 \%$ de los hogares dispone de uno o más televisor, dedicándole los adolescentes dos horas, de media, a prestarle su atención. Pero los/as jóvenes no utilizan la televisión para informarse, prefieren utilizar canales donde sean ellos/as quienes seleccionen la información que quieren recibir, estamos hablando de Internet. Havas Medias, realizó un estudio sobre cómo los jóvenes se informaban acerca del movimiento 15M, activismo consistente en fomentar la participación y representación de los/as ciudadanos/as, y el predominio en los poderes políticos (Mmovimiento15m.org, 2011). Para informarse sobre las actividades del movimiento, los jóvenes preferían Internet como primera opción con un $82 \%$, seguida de la televisión con un $71 \%$, y con medalla de bronce para la radio con un $39 \%$. Curiosamente la prensa, estimado por la sociedad en general como medios respetable obtenía un $42 \%$, ocupando el cuarto lugar como canal escogido por la audiencia más joven para informarse sobre el $15 \mathrm{M}$. $\mathrm{Si}$ segmentamos los canales que eligen para informarse dentro de Internet nos encontramos con la prensa on-line (71\%)y la red social Facebook con un 52\%, seguida por Twitter con un 28\% (233grados.lainformacion.com, 2011).

Este aumento de la interacción de los/as jóvenes en los medios de comunicación y las nuevas tecnologías, ha hecho que muchas personas se preocupen por la influencia sobre el desarrollo de su público juvenil, ya que por norma suele denominarse negativamente la influencia que los medios transmiten a los/as jóvenes. Así, a la televisión se le otorga el mérito directo de promocionar el consumo de alcohol, propiciar la actividad sexual precozmente y la fortalecimiento de estereotipos de género. Las películas y los videojuegos son denominados como provocadores de actitudes agresivas. Las publicaciones en prensa o revistas son culpables de aumentar la utilización de la figura femenina ideal como origen de trastornos de alimentación y problemas de autoestima sobre todo entre las jóvenes. $Y$ por último Internet, como medio masivo de violación de la privacidad y fomento de la cultura sexual (Oliva, A. 2003 p.377). Pese a todas estas acusaciones, los responsables de los jóvenes continúan comprándoles televisores para meterlos en sus cuartos, contratan la banda de Internet más rápida del mercado y les dan dinero para la compra de revistas y escapadas al cine. Sería como si instaláramos un botiquín en el cuarto de los/as niños/as y le echáramos las culpas porque han tocado el instrumental. No todos los contenidos son acertados, pero no podemos culpar a la canguro Internet o Televisión, de lo mal que han educado a nuestros jóvenes si son los propios padres y madres quienes les permiten el acceso sin restricciones. Desde este estudio no se pretende coarta la libertad de la juventud, ni se comparte la visión de los medios citada en las anteriores líneas, al contrario, se pretende cambiar la imagen que se tiene de los medios, a través de programas y contenidos que fomenten la cultura emprendedora, ayudando a la socialización. Algunos estudios han encontrado efectos positivos sobre el desarrollo adolescente derivados del uso de videojuegos (Phillips, Rolls, Rouse y Griffiths, 1995; Durkin y Barber, 2002), de la exposición a programas televisivos (Mares, 1996), o de la utilización de Internet (Conde, Torres-Lana y Ruiz, 2002; Hellenga, 2002).

La industria de contenidos digitales en España generó un volumen de negocio legal de $1.510,9$ millones de euros en el segundo semestre de 2010. A esta cifra debemos 
sumarle 5.562,1 millones de euros, valor total de los contenidos pirateados, segmentados en un $97,9 \%$ en el sector de la música, seguido de las películas con un $75,8 \%$, libros con un $43,5 \%$ y la creciente descarga ilegal de videojuegos con un 66,2\%. (Achaerandio, R. 2010). España es la cuarta potencia en el consumo de videojuegos y la sexta a nivel mundial (Pérez, Francisco 2010 p226). El campo de los videojuegos podría despuntarse como promotor de la cultura emprendedora. Los juegos sociales, juegos donde hay más de un jugador con un perfil y resumen de su juego, reciben su nombre por situarse en plataformas sociales, ofreciendo a los/as usuarios/as una identidad y la posibilidad de entablar una comunicación directa con otros usuarios/as (Vicente, J. 2010). En 2009 un 68,4 \% de los consumidores optó por comprar videojuegos en la categoría de simulación de la vida, aumentando este porcentaje en 2010 al 74,8\% (Adese, 2010). Esta tendencia por trasladar la vida real al videojuego es muestra de la posibilidad de realizar lo que queremos hacer y no nos atrevemos en la realidad. La ausencia de riesgos, la posibilidad de cometer errores y sobre todo la no exposición a ser juzgado, hacen que los juegos sociales aumenten. Incluso juegos como Farmville, de la red social Facebook, donde las personas registradas deben sacar adelante una granja (cultivando, recolectando y vendiendo) ha causado furor, aportando el $30 \%$ de los ingresos de la red social, y esperan que generen más de 1.000 millones de dólares en 2012. (Eldiariodeljuego.com 2011).

Si encontramos personas que dedican gran parte de su tiempo de ocio (y seguramente de trabajo) a llevar adelante una grana, ¿por qué no lo harían en la realidad? La respuesta es sencilla, pónganse en el lugar de ir a su pareja, familia y amigos/as y comentarle que se va a montar una granja. Seguramente las risas estarían aseguradas, sazonados con chistes y comentarios irónicos. Posteriormente, una vez que se han dado cuenta que su idea va enserio, intentarían convencerle de que la dejara, aunque sus amistades nunca hayan tenido una granja y no sepan de empresas agrícolas. Le invitarían que continuara con su trabajo o labor actual y no se complicara la vida. Todo este desanimo incluyendo las dificultades propia de iniciar un nuevo proyecto, les llevaría a desechar la idea de crear su granja real, es decir una vez más no se propiciaría la cultura emprendedora.

Hablar es música, y desde el principio de los tiempos, comenta Diana Navarro, cantante y compositora, cuando nos formamos en el vientre de nuestra madre lo primero que sentimos es la musicalidad de su voz. La música nos puede dar ideas absolutamente para todo, para un plato de cocina, para un cuadro, para un proyecto social, personal, y un largo etcétera. Todas las personas se identifican con un tipo de música, y cuando sentimos según qué tipo de estado de ánimo acudimos a este arte para potenciarlo o tranquilizarlo. Canciones como Eye of the tiger de la película Rocky III, dirigida y protagonizada por Sylvester Stallone, o la canción de la película Flashdance, de Adrian Lyne, titulada What a Feeling, son claros ejemplos de sintonías que nada más comenzar a escucharlas reconfortan nuestro estado de ánimo, se va generando una energía en nuestro interior, porque estas canciones son sinónimos de superación. En la trama de ambas se nos presentan a dos jóvenes que desean conseguir triunfar en lo que les gusta hacer, desarrollando y potenciando su creatividad, su talento, su elemento con el que se encuentran cómodos en su vida, y quieren que así siga siendo en su futuro. Por su parte, en la letra de las canciones 
podemos leer "no hay que perder el control sobre tus sueños, hay que luchar para mantenerlos con vida" en la canción Eye of the tiger, y en la canción What a Feeling podemos escuchar: "primero, cuando no hay nada pero hay un sueño pequeño creciendo, agarra tu pasión y haz que suceda". Ambas canciones transmiten el esfuerzo de dos jóvenes que lucharon por lo que deseaban llegar a ser en la vida, aprendiendo de las dificultades y mejorando con cada nuevo error, dos productos audiovisuales que tras más de veinticinco años de su publicación siguen transmitiendo el sentimiento de lucha por lo que quieres, o lo que se traduce hoy día como ser emprendedor/a.

La televisión, es otro gran creador de conciencia social, apartándonos de los informativos y programas de televisión que pueden ser juzgados por defender diferentes climas políticos, la ficción es un gran campo donde se podría plantar la cultura emprendedora. Series de televisión como Fame o Un paso adelante, o más recientemente el concurso Fama, a bailar, han elevado la cultura de las artes escénicas como una opción al mercado laboral de muchos jóvenes, y no porque hasta ahora no tuvieran oportunidad, si no porque es en este momento, cuando la sociedad apoya a las personas que se dedican al baile, personas que no han querido estudiar matemáticas, biología o derecho y gracias a estos contenidos televisivos el camino se les ha transformado en una pendiente menos elevada. La cadena pública estadounidense PSB ha creado una miniserie titulada America in Primetime(PBS 2011) donde el documental muestra las series como reflejo de la sociedad estadounidense. La mujer independiente, el hombre de la casa, la persona inadaptada o el cruzado son los cuatro estereotipos que creadores, actores, guionistas y productores han analizado en este documental, dejándonos conclusiones como que el rol del hombre y la mujer han ido cambiando en estos últimos años en la vida real y en la ficción. Por su transmisión de estereotipos, la televisión se presentaría como un gran escenario para propulsar la figura de la persona emprendedora con ejemplos reales, donde la audiencia pueda ver la creatividad, innovación, los medios que tuvieron a la hora de emprender. Con este tipo de contenidos favorecerían la confianza del emprendedor, al conocer otros casos y situaciones en la que se encuentra cualquier emprendedor, y de una manera más global, se comenzaría a incrementar la importancia de ser emprendedor en la sociedad. Las series suelen crear muchas corrientes de opinión e influyen en la sociedad ¿Cuántos habrán querido ser médicos por Urgencias o por Anatomía de Grey? Yo mismo quise ser agente de jugadores después de ver Jerry Maguire, comenta Jonay Sosa, creativo publicitario en Saatchi \& Saatchi.

Los contenidos de ficción son los primeros en mostrar a las personas nuevas realidades, incluso profesiones que desconocíamos, y por consiguiente permiten insertar en la mente de la audiencia la idea de generar nuevas conexiones entre puntos completamente paralelos, alentar desde la ficción, lo onírico, a arriesgarse a conectar dos contrarios para así crear un nueva respuesta, y una vez que este proceso se repita, estaremos ante personas capaces de generar ideas. Los medios de comunicación se postulan como los guías adecuados para favorecer el fomento de la cultura emprendedora a través de la creación de un clima social favorable. 
El ambiente es muy importante para realizar cualquier acto. Si pretendemos que los/as jóvenes apliquen lo aprendido en la nueva escuela que enseña cultura emprendedora, les pedimos que sean creativos, innovadores, emprendedores y arriesguen no lo van a hacer a no ser que se encuentren en un clima donde se sientan seguros. Si se plantan en un clima donde se les tachará de fracasados si el proyecto sale erróneo, o piensan que podrán defraudar a sus cercanos, las personas emprendedoras se negarán a crear y volverán a la fila junto con el resto, utilizando sus energías para buscar una salida de este clima bajo el que son observados todos sus movimientos, en vez de aprovechar esas energías en nuevas ideas.

Cuando una persona se siente rechazada por otra, esto puede traducirse como "menuda chorrada de idea", es decir una persona anula a otra, la persona afectada creará un sentimiento de rechazo hacía la otra, creando una especia de venganza, que se disparará cuando la persona culpable lance su idea, argumentando de todas las maneras posible por qué su idea no es necesaria, efecto rebote. Es muy importante reconocer la diferencia, no hay que hacer mutismo cuando una idea de otra persona me ha llevado a mí hasta otra, porque si no lo hubiera puesto encima de la mesa a mi seguramente no se me hubiera ocurrido mi idea. En definitiva, no coartemos la creatividad, reciclemos todas las ideas y fomentemos el espíritu emprendedor.

En este trabajo, hemos comentado la importancia de aglutinar a los/as emprendedores/as en un pensamiento con fuerza, que luche por sus intereses, sobre todo los de carácter cultural, es decir crear un think tank que defienda la cultura emprendedora y lo mantenga en el huracán de la información diaria. Un poder informativo como este, ayudaría a la creación de este clima pacífico hacia la figura del emprendedor. Mantener una difusión constante y eficaz de la iniciativa emprendedora a través de los canales de información posibles, eliminando los intermediarios en los canales de participación para que la información llegue a tiempo y utilizando cauces próximos a la realidad de la comunicación juvenil, como las redes sociales (Consejo de la Juventud de España 2011). Además otra herramienta comunicacional que ostentan las empresas es la del mecenazgo. La actividad del mecenazgo, cuyo fin es responder a intereses generales, públicos y comunes (Méndiz, A. 2007 p.28) podría proclamarse como una actividad de responsabilidad social corporativa por parte de las empresas, de ayudar a los jóvenes emprendedores en el inicio de sus proyectos. En la terminología emprendedora, existen los llamados bussines angels, individuos que invierten en las primeras fases de creación de una empresa, ayudando a hacer realidad el proyecto emprendedor (Alemany 2011 p.75), aunque existe un término, en España no existen demasiadas fuentes de financiación de emprendedores. Como mencionábamos anteriormente, la falta de confianza es uno de los principales problemas para depositar compromiso en los proyectos.

La comunicación, permitirá la creación de un mercado pacífico. A diferencia de cualquier competición o trabajo, donde para que una persona gane o ascienda otra debe perder, el panorama laboral que creará la cultura emprendedora será el de la colaboración. Un proyecto saldrá adelante sin necesidad de destruir a otro, será posible la coexistencia de varios, porque el emprendimiento aboga por la conexión de 
planos de actuación diferentes pero unidos, evitando las envidias y con ello una meta destructora de nuestra competencia.

Los medios de comunicación son una herramienta clave para alzar la imagen de la cultura emprendedora y favorecer su integración en la sociedad, como generadores de ejemplos de cultura emprendedora que la hagan más cercana y palpable de lo que se puede conseguir con ella. La comunicación se contempla como un todo, donde caben acciones propias tanto de la publicidad y las relaciones públicas como del periodismo $O$ la comunicación audiovisual (Almansa, A 2005 p.131). Si todos los canales aportan a sus contenidos cultura emprendedora contribuirán a eliminar muchos prejuicios colectivos existentes y a mejorar las relaciones sociales e incluso intergeneracional, puesto que a propiciará la tolerancia de ideas, la colaboración entre personas sin importar sus estudios, edad o cualquier otro factor, para generar nuevas ideas.

Por tanto, los media fomentarán un clima de colaboración, lo que no significa que el riesgo sea cero, pero el apoyo mutuo, alabar la ilusión por emprender de las personas, de perseguir sus metas, fortalecerá la seguridad del emprendedor para arriesgarse con proyectos creativos e innovadores, en pensar algo distinto y su posterior implantación a una sociedad que lo acepta.

\section{CONCLUSIONES}

La educación es fundamental en el ser humano, por ello desde este proyecto se apoya la idea de instaurar la cultura emprendedora en el sistema educativo. Sin embargo si les queremos enseñar a los profesionales del mañana a que sean creativos, innovadores, responsables y emprendedores, no solo debemos cambiar el contenido de las materias, también las infraestructura. Es decir debemos ser cautos, no debemos enseñar un modelo de cultura emprendedora, porque si así fuera estaríamos volviendo al pensamiento unitario, anulando la creatividad. Esto se podría evitar mostrando casos de personas que han sido emprendedoras, pero sin quedarnos con el ejemplo como modelo a seguir, si no únicamente como una persona que logró algo gracias a la implantación de la innovación. Una concepción que se transmitiría sin problemas a través de documentales, libros, películas, reportajes o canciones. Por tanto estamos convirtiendo a los medios de comunicación en el principal aliado del fomento de la cultura emprendedora.

Los/as jóvenes españoles poseen un gran temor a arriesgarse a ser diferentes. Esta falta de confianza se convierte en un ancla para los valores de la cultura emprendedora, impidiéndoles surcar nuevos horizontes donde conquistar nuevas tierras cubiertas de innovación. Los medios de comunicación, se convertirían por tanto en la avanzadilla de las personas emprendedoras creando un clima favorable para que las personas emprendedoras puedan desarrollarse. Puesto que si educamos desde ahora a los jóvenes en cultura emprendedora, aún tendremos un desfase intergenracional con la audiencia que no ha crecido con la idea de innovación, creatividad, responsabilidad y emprendimiento, y continuaríamos manteniendo un grado de miedo a fracasar ante este grupo que no ha sido educado en la cultura emprendedora. Por tanto, los media serían la perfecta herramienta de 
socialización, gracias a su rapidez, transmisión de contenidos, y a la segmentación de sus públicos, se podrán crear espacios, programas, reportajes, películas, concursos, especiales para ese público que desconoce la cultura emprendedora, y por consiguiente la aceptación de esta figura.

La cultura emprendedora debe enseñar a forzar nuevas relaciones entre ámbitos distintos. Estas conexiones ayudarán a aportar nuevas soluciones, es decir es necesaria la diversidad en los contenidos para que al juntarlos obtengamos una nueva visión. En esta materia los medios de comunicación son expertos. En la historia de la ficción nos hemos encontrando grandes relatos que nos han hecho reír, llorar, asustarnos y creado todo tipo de mundos y de pensamientos, e incluso descubierto profesiones que hasta el momento desconocíamos de su existencia. Todo ello, gracias a que las tramas que se nos presentaban contaban historias que los espectadores nunca hubieran imaginado en la realidad, o lo que es lo mismo carencia de creatividad e innovación. Los media a través de diferentes tramas aportarán nuevas conexiones de polos opuestos, incitarán a las personas a atreverse a adoptar esta actitud de generar conexiones, iniciar el proceso creación e innovación, puesto que es más fácil ver algo para después creer en ello.

Todos somos especiales. Hasta el momento los contenidos de los medios de comunicación nos han llevado a creer que necesitamos encontrar a otra persona para completarnos. Nacemos enteros y la singularidad de cada uno nos hace especial. Reforzar esta confianza en uno mismo, es la que se debe transmitir desde los medios de comunicación. Olvidemos por un tiempo la necesidad de encontrar a otra persona que nos complete por la de encontrar a otra persona que al conectarnos, cada uno en su totalidad surjan nuevas ideas. Extrapolado al mundo laboral, nos encontramos con los líderes, personas a las que cargamos con todo el peso de crear e innovar, puesto que es más cómodo seguir lo que nos dicten que ponernos a pensar en soluciones. Lo que ocurre es que la inteligencia más enriquecedora, es la que se crea del pensamiento colectivo. Confianza en nosotros mismos, resaltar la figura de la singularidad, puesto que es mucho más fácil ser uno más, debemos invitar apostar por ser original, lo que nos repercutirá en coraje, valor e ilusión para seguir adelante con cualquier idea que queramos proponer.

Aceptación del fracaso. En el mundo de la investigación es común aceptar los errores, puesto que los procesos metodológicos se utilizan para obtener errores de cómo no se debe continuar una investigación. Sin embargo, en el mundo social, los errores son convertidos en fnes. Cuando una persona emprendedora ha fracaso en su idea de proyecto, se le anima a abandonar con la tarea, y volver a buscar una solución común, menos arriesgada. Debemos educarnos en el error, porque es lógico que si somos creativos y arriesgados, tenemos más probabilidades de obtener más errores que aciertos. La sociedad debe comprender que gracias a estos errores podremos ir acercándonos al acierto. Las noticias y reportajes deberán fomentar la cultura del error, mostrar noticias donde se fracasa pero desde un punto de vista afortunado. Si una puerta no se puede abrir, ya sabemos que no se puede abrir, con lo cual no será necesario prestarle más atención, pero para llegar hasta esta conclusión, hemos tenido que arriesgarnos a ponernos delante de la puerta e intentar 
abrirla, al final hemos obtenido una respuesta: no volver a esa puerta porque estará cerrada. Los medios de comunicación si trabajan en este sentido, conseguirán dejar puertas abiertas a los/as emprendedores/as.

Compromiso con la cultura emprendedora. Los medios de comunicación deben comprometerse en el fomento de la cultura emprendedora. Ser los primeros en invertir esfuerzos por hacer germinar la cultura emprendedora. En los contenidos que reflejan los medios, al igual que donde se encuentra anclada la educación, se nos enseñan muchos valores pragmáticos, originarios de un contexto al que nos han enseñado a guardar fidelidad a lo establecido. Este respeto hacia los valores pragmáticos está reforzados por la ética, el respeto, un respeto que debemos procesar hacia el pensamiento que es aceptado por todos los ciudadanos. Sin embargo en el actual estancamiento de pensamiento pragmático surge un nuevo valor, el valor de la poiesis, o lo que es lo mismo el valor de las posibilidades, donde se encuentra la creatividad, porque la creatividad son nuevas posibilidades. Si tuviéramos que situar el sistema educativo y comunicacional actual en el lado de uno de estos valores, los colocaríamos en la parte pragmática, porque estamos mucho más orientados hacia el pragmatismo, lo racional, lo que conlleva una atrofia de la ética y de culto a lo emocional. El equilibro de estos valores otorgará confianza a las persona, por tanto serán los medios de comunicación quienes sustenten la responsabilidad de transmitir una comunicación capaz de mantener una coherencia al combinar los valores pragmáticos, éticos y emocionales.

Ilusión. Si hay una verdadera fábrica que hace realidad las ilusiones son los medios audiovisuales. Gracias a películas, anuncios e historias de televisión hemos conocido extraordinarios parajes y mundos de fantasía que sin, la creatividad y la valentía de guionistas y productores, actores y actrices que materializaron ese proyecto no hubiera sido posible. Se debe continuar alimentando la ilusión, porque un trabajo bien hecho es aquel que se ha hecho con ganas, con amor. Aunque nos pueda sonar a literatura, la ilusión impregna cada investigación, hallazgo arqueológico, creación de una empresa, la ilusión de llegar a cabo una idea, que surgió de un pensamiento creativo e innovador. Así, continuemos consumiendo productos audiovisuales que hagan ilusionarnos en nuestro día a día, porque personas ilusionadas, son personas con perseverancia para llevar a cabo su trabajo, restándole importancia a los agentes externos opositores a su idea. En el momento que la ilusión se va, el emprendimiento se marcha con ella. Pero si ilusionamos y encima resaltamos la figura de estas personas ilusionadas, podrán conectarse, hacerse más fuerte contra el desapego generalizado, porque la unión hace la fuerza no es nuevo, pero si debemos de recordarlo, que como nosotros seguramente ahora mismo alguien está pensando en una idea que quizás es irrisoria para presentarla ante un público, pero es la ilusión la que decanta la balanza para que siga adelante.

Los medios de comunicación, como líderes de opinión pueden generar debates en la sociedad, la llamada agenda setting (Noam Chomsky) teoría sobre cómo los medios influyen directa o indirectamente en la preocupación de la ciudadanía por unos temas más que otros al situarlos en sus espacios informativos. Estos debates que pueden propiciar en los/as ciudadanos/as pueden ser con un carácter de inicio, cuando 
surge un tema hasta del que hasta ahora nunca se ha hablado; de mejora, debates donde se sigue trabajando en una temática, y debates de reinvención, es decir todas las personas cogemos algo que conocemos y le otorgamos de forma colectiva un nuevo significado. Ante este poder que poseen los medios como líderes, deben poner sobre la mesa el tema de la cultura educacional actual, para que entre todos los participantes de la sociedad reinventemos la cultura actual por la emprendedora, porque su filosofía es generar ideas que funcionan para el bien común, entre todos, aportando actividades y soluciones en la que hasta ahora no nos habíamos puesto a pensar, porque estábamos preocupados por otros temas que leíamos o escuchábamos en los media.

\section{BIBLIOGRAFÍA}

Bernays, E. (2000) Cristalizando la opinión pública. Barcelona. Gestión.

Blanchet, A.; Ghiglione, R. Massonnat, J.; Trognon, A. (1989)Técnicas de investigación en Ciencias Sociales: datos, observación, entrevista, cuestioario. Madrid. Narcea.

Campmany, J. (2005) El efecto ZP. 1000 días de campaña para llegar a la Moncloa. Planeta.

Casson, M.C. (1982). The Entrepreneur. An Economic Theory. Oxford: Martin Robertson.

Fundación Audiovisual Andaluza (2010). Contenidos Audiovisuales 2.0. Fundación Audiovisual Andaluza.

Gasalla Dapena, J.M. (2011). Asunto: confianza y compromiso. LID.

Méndiz, A. (2007). Nuevas formas publicitarias. Patrocinio, Product Placement, Publicidad en Internet. Universidad de Málaga.

Kirzner, I. M. (1979) Perception, Opportunity and Profit. Chicago: University of Chicago Press.

Alemany, L; Álvarez,C.; y Urbano,D. (2011). Libro blanco de la iniciativa emprendedora en España. Fundación Príncipe de Girona. 166.

Castells, M. (1997) La era de la información. Economía, Sociedad y Cultura. Madrid. Alianza Editorial.

Clouse, V.G.H. (1990). A Controlled Experiment Relating Entrepreneurial Education to Students' Start-up Decisions. Journal of Small Business Management, 28(2), 45-53.

Gartner, W.B. (1990). What are we talking about when we talk about entrepreneurship? Journal of Business Venturing, 5, 15-28. 
Herrera Echeverri, H. (2009) Investigación sobre redes sociales y emprendimiento: revisión de la literatura y agenda futura. Innovar, 19-33.

Hills, G.E. (1988) Variations in University Entrepreneurship Education: An Empirical Study of an Evolving Field. Journal of Business Venturing, 3,109-122.

Hindle, K. (2002). A Grounded Theory for Teaching Entrepreneurship using Simulation Games. Simulation \& Gaming, 33(2), 236-241.

Jones, C. y Thornton, P.H. (2005) Transformation in cultural industries. Research in the Sociology of Organizations, 23. JAI Press Inc.

Kirby, D. (2004) Entrepreneurship education: can business schools meet the challenge? Education and Training, 46(8/9). 510-519.

Kuratko, D.F. (2005) The emergence of entrepreneurship education: development, trends and challenges. Entrepreneurship Theory and Practice, 29(5), 577-597.

Mair, J. y Martí, I. (2006) Social entrepreneurship research: A source of explanation, prediction and delight. Journal of World Business, 41 (1), 36-44.

McMullen, W.E. y Long, W.A. (1987) Entrepreneurship Education in the Nineties. Journal of Business Venturing, 2(3), 15-29.

Megías Quirós, I.; Rodríguez San Julián, E.; Sánchez Pardo, L. (2004) Jóvenes y publicidad. Valores en la comunicación publicitaria para jóvenes. ISBN 84-95248-30-1.

Miles M.P. y Covin J.G. (2002) Exploring the practice of corporate venturing: Some common forms and their organizational implications". Entrepreneurship Theory and Practice, 26(3), 21-40.

Olaz, A. (2008) Le entrevista en profundidad. Justificación metodológica y guía de actuación práctica. Septem Ediciones.

Oliva, A. (2003)Adolescencia en España a principios del siglo XXI. Cultura y educación. Universidad de Sevilla 373-383.

Peredo, A.M. y McLean, M. (2006). Social entrepreneurship: A critical review of the concept. Journal of World Business, 41, 56-65.

Robinson, K. (2009) El elemento: descubrir tu pasión lo cambia todo. Grijalbo.

Robertson, M. y Collins, A. (2003) The Video Role Model as an Enterprise Teaching Aid. Education \& Training, 45(6), 331-340. 
Ruíz, J.I. (2007) Metodología de la Investigación cualitativa. 4a edición. Bilbao Universidad de Deusto.

Sexton, D.L. y Upton, N.B. (1987) Evaluation of an Innovative Approach to Teaching Entrepreneurship. Journal of Small Business Management, 25(1), 35-43.

Scott, M.G. y Twomey, D.F. (1998) The Long Term Supply of Entrepreneurs: Student's Career Aspirations in Relation to Entrepreneurship. Journal of Small Business Management, 26(4), 5-13.

Solomon, G.T.; Weaver, K.M.; y Fernald, L.W. (1994) Pedagogical Methods of Teaching Entrepreneurship: An Historical Perspective. Gaming and Simulation, 25(3), 338-253.

Van Stel, A.; Carree, M. y Thurik, R. (2005) "The effect of entrepreneurial activity on national economic growth". Small Business Economics, 24, 311-321.

Vesper, K.H. y McMullan, W.E. (1988). Entrepreneurship: Today Courses, Tomorrow Degrees? Entrepreneurship Theory and Practice, 13(1), 7-13.

BOJA núm. 137 (2011) Decreto 219/2009, de 28 de junio, por el que se aprueba el Plan para el Fomento de la Cultura Emprendedora en el Sistema Educativo Público de Andalucía. Recuperado el 5 de Julio de 2011, de http://www.juntadeandalucia.es/boja/boletines/2011/137/d/1.html

Adese (2010). Balance económico de la industria del videojuego 2010. Recuperado 22 de Octubre de 2011 de www.adese.es/pdf/dossierbalanceeconomico2010.pdf

Almansa, A. (2005). Relaciones Públicas y gabinetes de comunicación. Facultad de Ciencias de la Comunicación. Universidad de Málaga. Recuperado el 2 de Octubre de 2011, de ddd.uab.es/pub/analisi/02112175n32p117.pdf p. 117-132

Carrasco, S. (1999) Indicadores culturales: una reflrexión. Universidad de Valencia. Recuperado 21 de Octubre de 2011 , de www.uv.es/carrascs/PDF/indicadoresCult.pdf

Comisión de las Comunidades Europeas (2003). Libro verde. El espíritu empresarial en Europa. Bruselas.

http://eurlex.europa.eu/LexUriServ/site/es/com/2003/com2003_0027es01.pdf.

CISCO (2011). Cisco Connected World Technology Report. 2011. Recuperado el 29 de Octubre de 2011, de www.cisco.com/en/US/netsol/ns1120/index.html.

Infoadex (2011) Estudio de la inversión Publicitaria en España resumen 2011. Recuperado el 23 de Septiembre de 2011, de www.infoadex.es/RESUMEN2011.pdf 
Nuevas Tecnologías - Cultura Emprendedora - Medios de Comunicación - Innovación

EGEDA (2011) Paronama audiovisual 2011: primeros datos de la transición al digital. Recuperado el 23 de Deptiembre de 2011, de www.egeda.es/EGE_LibrosPanorama2011.asp

Martín, S. y Velarde, O. (2001). Informe Juventud en España 2000. Edición Injuve. Recuperado el 25 de Septiembre de 2011, de

http://www. injuve.es/contenidos. .tem .actionid $=605169259 \&$ menuId $=1627100828$

Tuenti (2011). Encuesta: Impulsa tu futuro. Recuperado el 3 de Septiembre de 2011, de

http://www.google.es/url?sa=t\&rct=j\&q=tuenti\%20impulsa\%20tu\%20futuro\&source=web\&c $\mathrm{d}=1 \&$ ved=0CCWQFjAA\&url=http\%3A\%2F\%2Fes.forumimpulsa.org\%2F2011\%2Fupload\%2Fa partat\%2Ftuentiimpulsa-tu-

futuro2010.pdf\&ei=t6_STpXvL4e_8wPKzbDNDw\&usg=AFQjCNHUoUGVrlEhzIRJqA77GbGstyOI Wg\&sig2=sS6qYs5IhaHwJkrWOhffeg\&cad=rja

Tello, B. (2010) Guía de Think Tank en España. Fundación Ciudadanía y Valores. Recuperado el 4 de abril de 2011, de

www.funciva.org/publicaciones/think-tanks.pdf

Universidad Camilo José Cela (2011). Generación 2.02011 Hábitos de usos de las redes sociales en los adolescentes de España y América Latina. 2011. Recuperado el 18 de Septiembre de 2011, de http://www.slideshare.net/ucjc/generacin-20-2011-hbitosde-usos-de-las-redes-sociales-en-los-adolescentes-de-espaa-y-amrica-latina

233grados.lainformacion.com (2011). Los jóvenes españoles prefieren seguir el 15M por internet. Recuperado el 18 de Julio de 2011, de http://233grados.lainformacion.com/blog/2011/06/15m-televisi\%C3\%B3n-j\%C3\%B3venesinternet.html

ATA Federación de Autónomos (2011). Informe jóvenes emprendedores-Unión Europea. Recuperado el 16 de Septiembre de 2011, de www.ata.es/imagenes/publicacionesPdf/publicacion55.pdf

Castillo, A. (2009) Relaciones Públicas y Think Tanks en América latina. Estudio sobre su implicación y acción. Razón y Palabra. Recuperado el 13 de Octubre de 2011, de www.razonypalabra.org.mx/N/N70/Castillo_revisado2.pdf

Eldiario.deljuego.com.ar (2011). Las 5 tendencias Impulsadas por los medios sociales que harán furor en 2012. Recuperado el 30 de Noviembe de 2011, de http://eldiario.deljuego.com.ar/es/submenuanalisisdelarealidad/2219-las-5-tendencias-queseran-impulsadas-por-los-medios-sociales-en-2012.html

Filmaffinity.com. Flashdance. 1983. Disponible en: http://www.filmaffinity.com/es/film669395.html 
MCU-Emprendedores (2011). Crea tu plan de negocio. Ministerio de Cultura. Madrid. Recuperado el 2 de Septiembre de 2011, de http://www.mcu.es/emprendedores/Inicio.html

Ministero de Educación (2011). Datos y Cifras 2010-2011. Recuperado el 9 de Septiembre de 2011, de

http://www.google.es/url?sa=t\&rct=j\&q=educaci\%C3\%B3n\%20en\%20espa\%C3\%B1a\%2020 $11 \&$ source =web\&cd=9\&ved =0CGQQFjAI\&url=http\%3A\%2F\%2Fwww.educacion.es\%2Fdctm \%2Fministerio\%2Fhorizontales\%2Fprensa\%2Fdocumentos\%2F2010\%2Fseptiembre\%2Fdatos -y-cifras-2010-

2011.indd.pdf\%3FdocumentId\%3D0901e72b803eceed\&ei=78DSTt2BCtLC8QPBtI3jDw\&usg=A FQjCNHEenk1kuTBiF-HaVECYex_CweAVg\&sig2=hk6gLiqjl2XRE0dbLnqJsQ\&cad=rja

Movimiento15m.org (2011). Sobre Movimiento 15M.org. Recuperado el 5 de Octubre de 2011, de http://movimiento15m.org/sobre-movimiento-15m-org/

Jiménez, M. (2011). Un gallego crea una red social para emprendedores. Cincodias.com. Madrid. Recuprado el 3 de Septiembre de 2011, http://www.radiocable.com/facbook-emprendedor662.html

Redes. (2011). Todos tenemos la capacidad de ser creativos. . Recuperado el 13 de Abril de 2011, de http://www.rtve.es/television/20110327/todos-tenemos-capacidad-sercreativos/420223.shtml

Simón, A. (2011) Entrevista a Pedro Moneo: las empresas quieren contratar emprendedores. Cincodias.com. Recuperado el 9 de Septiembre de 2011, de http://www.cincodias.com/articulo/directivos/empresas-quieren-contrataremprendedores/20111008cdscdidir_2/

El País (2011) Elija su propia aventura. Disponible en:

http://www.elpais.com/articulo/madrid/Elija/propia/aventura/elpepiespmad/20111126elpmad_ $1 /$ Tes

Injuve. (2011)Encuesta de Población Activa (EPA). 30 trimestre 2011. Principales resultados jóvenes 16-29 años. Total Estatal, Comunidades y Ciudades Autónomas. Observatorio de la juventud en España.2011. Recuperado el 18 de Septiembre de 2011, de www.injuve.es/contenidos.downloadatt.action?id=1829757437

Ovelar, M. (2011) Mi start up. El País. Artículo publicado el 1/07/10. Recuperado el 10 de Julio de 2011, de http://www.elpais.com/articulo/portada/start/up/elpepisupcib/20100701elpcibpor_2/Tes

Ávalos, F. (2011) Libera todo tu potencial. Conferencia Netday. Málaga. 20/10/11.

\section{Juan De Lucas Osorio}


Responsable de imagen off-line y online de la Asociación Arrabal-AID, docente en ponencias y cursos de comunicación social y emprendimiento. Diseñando su carrera hacia una comunicación solidaria, la visibilidad del Tercer Sector y la inclusión social a través de la comunicación, le han llevado a crear proyectos como HEDE, asociación para el fomento de la cultura emprendedora. Pertenece al Consejo Social Penitenciario: Comisión Laboral a través cuya función es crear la campaña de concienciación empresarial hacia las personas ex-reclusas. Doctorando en la Universidad de Málaga para propiciar el emprendimiento a través de la comunicación. 